\title{
A Framework for Research Inventory of Manufacturing Sustainability Assessment
}

\author{
Ju Yeon Lee, Y. Tina Lee \\ Engineering Laboratory \\ National Institute of Standards and Technology \\ Gaithersburg, Maryland 20899, U.S.A
}

\begin{abstract}
There have been many research papers focused on development of guidelines, indicators, metrics, methods, tools, and systems - all related to sustainability performance assessment. However, manufacturing companies have difficulty in finding papers that are relevant to their sustainability goals and conditions. A research inventory is a data repository for storing research papers in a manner that makes them easy to retrieve. To be successful, therefore, the inventory must have a system for managing, in a systematic manner, the results generated by a large number of researchers around the world. In this paper, we propose a framework for a research inventory that focuses on papers that report on research related to manufacturing sustainability assessment. This proposed framework consists of two parts: an operational definition and a classification scheme. The definition distinguishes between those papers that belong in the inventory and those that do not. The classification scheme is used to tag/code papers for retrieval. We demonstrate the use of this proposed framework using the Sustainable Manufacturing Toolkit of Organization for Economic Co-operation and Development.
\end{abstract}

KEYWORDS: research inventory, manufacturing sustainability, manufacturing sustainability assessment, classification scheme

\section{INTRODUCTION}

The need for manufacturing companies to pursue sustainability goes beyond its societal importance. It is becoming an important prerequisite to ensuring their long-term survival in the globally competitive market. Consequently, the number of manufacturing companies that demand the ability to assess sustainability in their products and processes is increasing rapidly. This ability has been summarized in terms of sustainability accounting and impact analysis (Feng et al., 2010). Sustainability accounting means that resource utilization, waste generation, and pollution emission from all activities in manufacturing should be evaluated and documented for sustainability performance evaluation. Impact analysis includes the impacts on people's wellbeing, on the environment, and on the economy. Both should be evaluated against industry benchmarks using predefined, performance metrics based on sound, scientific research results. Many papers have been published describing such research results. 
Those results include guidelines, indicators, metrics, methods, tools, and systems -all related to sustainability performance assessment. However, it is often difficult to find papers that are relevant to the sustainability goals and conditions of specific manufacturing companies.

To overcome this difficulty, we recommend a research inventory. A research inventory is a repository of research papers and a system for managing those papers. The management system performs four major functions: decide which research is relevant, implement a classification to "tag" papers, archive papers to a physical repository, and respond to queries for papers. These functions make it possible for users to get a better understanding of the research landscape, to determine the current state-of-the-art and state-of-the-practice, and to identify gaps and recommend new research.

This paper focuses on developing a research inventory for papers that address research approaches ${ }^{1}$ relevant to manufacturing sustainability assessment (MSA). It addresses the first two management functions described above. It proposes a conceptual definition to decide relevant papers and a structural definition to classify those papers. A conceptual definition defines concepts and terminologies relevant to MSA. A structural definition defines a taxonomy or classification scheme of a research inventory.

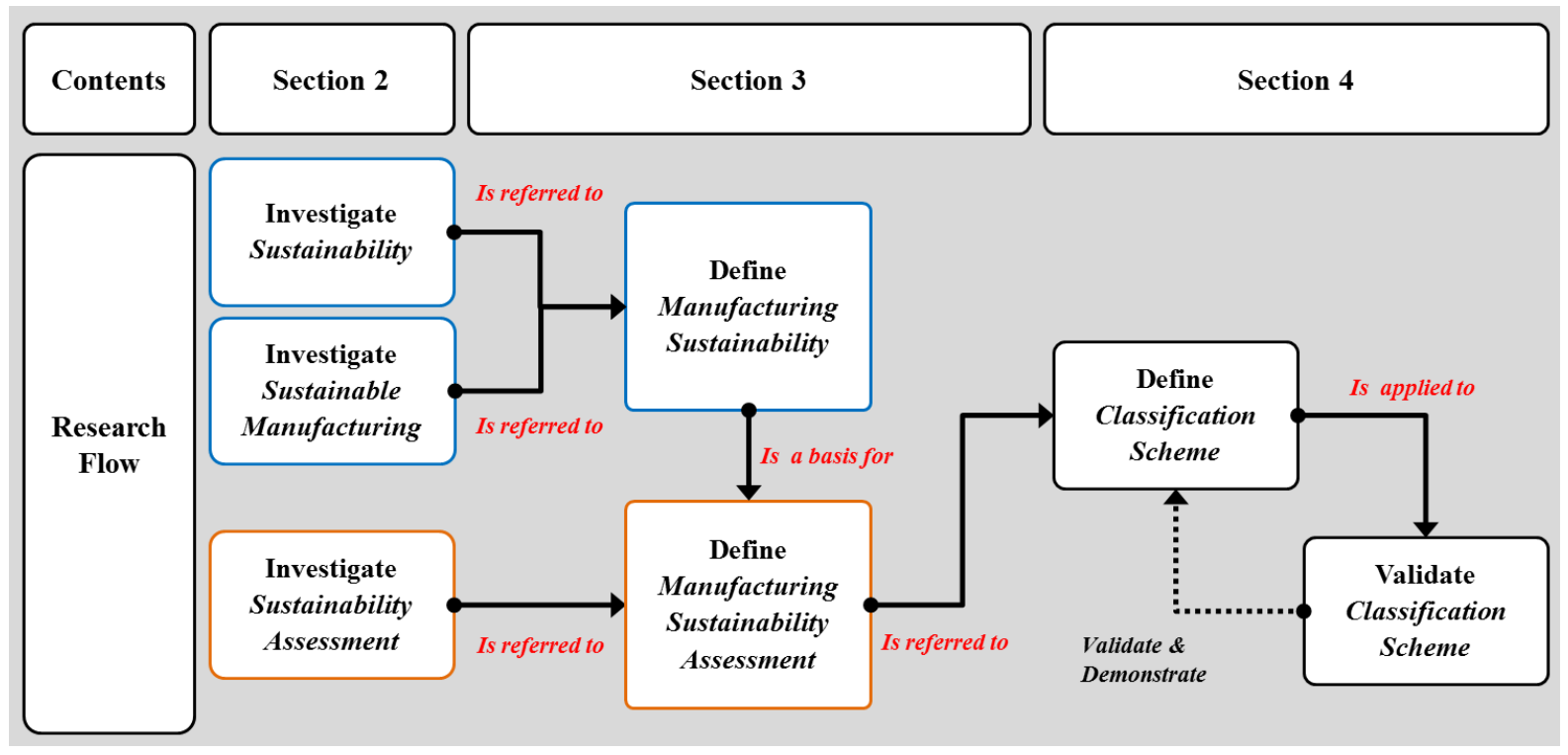

Figure 1. Research flow of main tasks and their relationships in the paper

Together, these definitions make up our research inventory. The framework is described in the remainder of the paper. Section 2 investigates the definitions of sustainability, sustainability assessment, and sustainable manufacturing, and reviews the literature on classification schemes.

\footnotetext{
${ }^{1}$ Approach is the method used or steps taken in setting about a task, problem, etc., or a means adopted in tackling a problem, job of work, and so on (Approach, 2012). In this paper, the term 'approach' is interpreted as a method, which is adopted from any type of means (e.g., tool, method, and methodology).
} 
Section 3 defines manufacturing sustainability and MSA in an operational way. Section 4 proposes the classification scheme with its notation for the MSA approaches. The classification scheme is demonstrated with an existing MSA approach. Section 5 summarizes contributions and future work. The research method for this paper is depicted in Figure 1, which shows the research flow of main tasks and their relationships.

\section{BACKGROUND \& LITERATURE REVIEW}

A variety of research inventories have been developed in accordance with their target research field and scope. The University of North California Institute for the Environment (UNC, 2010) developed a sustainable research inventory, which provides a comprehensive inventory of sustainability-related research initiatives. The European Science Foundation developed a portal called MERIL (Mapping of the European Research Infrastructure Landscape) to achieve a comprehensive inventory of research infrastructure $^{2}$ of major relevance in Europe across all scientific domains, accessible to the public through an interactive online portal (ESF, 2013). The International Society for the Psychoanalytic Study of Organizations provides an inventory for research that has been done by their society members (ISPSO, 2012). The Patient-Centered Outcomes Research Institute also started a project for a comprehensive inventory of clinical data and patient-powered research networks (PCORI, 2012).

Further investigation reveals that limitations exist with implementations of these research inventories. First, most research inventories provide a simple list of research papers. They only have the index information (e.g., a title and authors) for registration, tracking, and retrieving. Second, the target research fields and scope of the inventories are not specified clearly. For example, even though the inventory is for sustainability research, the definition of sustainability research is not clearly defined. Lastly, it is difficult to find a commonly accepted framework to implement a research inventory in a systematic manner. This could have been the fundamental cause for the limitations to existing research inventory schemes.

This section describes the definitions of sustainability, sustainability assessment, and sustainable manufacturing based on literature review. These definitions provide a basis to define the framework. Classification scheme for sustainability assessment is also discussed.

\subsection{Defining Sustainability}

The most widely accepted formal definition of sustainable development appeared in the 1987 World Commission on Environment Development (WCED) report (later published as a book, "Our Common

\footnotetext{
${ }^{2}$ A European Research Infrastructure is a facility or (virtual) platform that provides the scientific community with resources and services to conduct top-level research in their respective fields. This research infrastructure can be single-sited or distributed or an e-infrastructure, and can be part of a national or international network of facilities, or of interconnected scientific instrument networks (ESF, 2013). 
Future") as development that meets the needs of the present without compromising the ability of future generations to meet their own needs (Brundtland Commission, 1987; Labuschagne and Brent, 2005; Baumgartner, 2011). There have been more than 100 definitions of sustainability since the WCED definition (MSA, 2008). The Forestry Commission of Great Britain defined sustainability by adding four objectives to the WCED definition: social progress which recognizes the needs of everyone; effective protection of the environment; prudent use of natural resources; and maintenance of high and stable levels of economic growth and employment, as shown in Figure 2 (Forestry Commission of Great Britain, 2012). These objectives were generally referred to as three pillars or triple bottom line of sustainability (Earth Charter Initiative, 2000; Hardcastle and Waterman-Hoey, 2010). For instance, Beloff et al. (2004) defined sustainable development as a complex concept that encompasses the triple bottom line: the economic, environmental, and social factors that affect the ability of an organization to survive and grow.

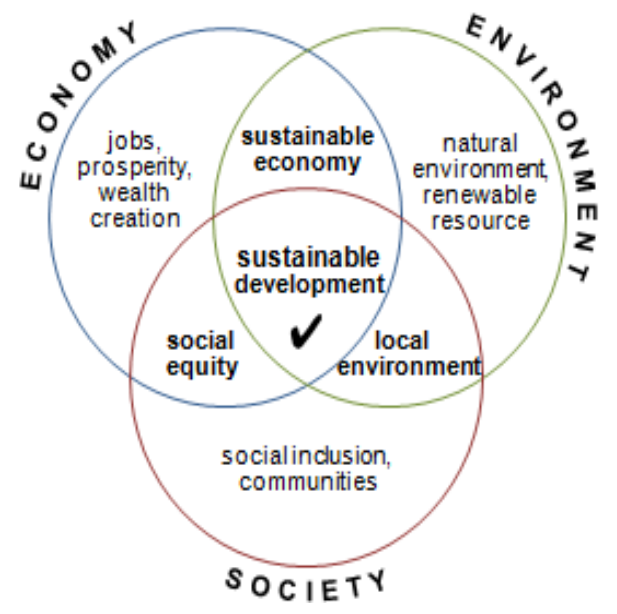

Figure 2. Sustainability definition from the Forestry Commission of Great Britain

According to the US National Research Council (US NRC, 1999), sustainability is the level of human consumption and activity, which can continue into the foreseeable future, so that the system that provides goods and services to the humans persists indefinitely. The National Risk Management Research Laboratory of US Environmental Protection Agency suggested that sustainability occurs when we maintain or improve the material and social conditions for human health and the environment over time without exceeding the ecological capabilities that support them (Sikdar, 2003). Australia's National Strategy for Ecologically Sustainable Development (1992) ecologically defined sustainable development as using, conserving, and enhancing the community's resources so that ecological processes, on which life depends, are maintained, and the total quality of life, now and in the future, can be increased. According to Hediger (2000), sustainability is a normative concept which involves trade-offs among social, ecological, and economic objectives, and is required to sustain the 
integrity of the overall system. Lozano (2008) proposed the Two Tiered Sustainability Equilibria (TTSE) adding time aspect to economic, environmental, and social aspects to explain sustainability. Do (2010) defined sustainability as the development concept and approach that realize social justice, maintain natural environment, and pursue economic prosperity with 3P (People, Planet, and Profit) and 3E (Equity, Environment/Earth, and Economy). Feng et al. (2010) defined sustainability in development as an organization's ability to advance its economic state without compromising the environment and the social equity that provide the quality of life for all community residents, present or future. There are currently many other definitions of sustainability and sustainable development. Glavic and Lukman (2007) clarified and classified the meaning and applications of 51 terms and their definitions related to sustainability for better understanding. To conclude, most definitions agree that the sustainability concept is designed to satisfy social, environmental, and economic goals despite various different purposes and perspectives.

\subsection{Defining Sustainability Assessment}

The pervasive growth of interest over the past few decades in the idea of sustainability or sustainable development has brought with it challenges associated with impact assessment. Assessment was defined originally in the late 1960s and early 1970s to focus on the environmental impacts. Recently, however, the focus has expanded to take into account the three pillars of sustainability (Pope et al., 2004). As a result, numerous assessment methods, across different disciplines, have been proposed. Buselich (2002) proposed that sustainability assessment as assessment of proposed initiatives (projects, policies and plans) in terms of sustainability to determine the conditions under which approval would be given. Hasna (2008) proposed adding a fourth dimension to the triple bottom line and that assessment be viewed as integrated assessment for assessing the social, environmental, technological and economic dimensions of projects, policies and programs (PPP). Ness et al. (2007) argued that sustainability assessment has increasingly become associated with the family of impact assessment tools consisting of e.g., Environmental Impact Assessment (EIA), Strategic Environmental Assessment (SEA), or EU Sustainability Impact Assessment (SIA). Devuyst and Hens (2001) defined sustainability assessment as a tool that can help decision-makers and policy-makers decide which actions they should or should not take in an attempt to make society more sustainable. According to Verheem (2002), the aim of sustainability is to ensure that plans and activities make optimal contributions to sustainable development. Understanding the general concept of sustainability assessment helps us to define MSA. Although most definitions of sustainability assessment have been defined from a business perspective, there is a common idea that sustainability assessment should support a decision-making associated with social, environmental, and economic performance.

There have been several research efforts on classifying the existing approaches for assessing 
sustainability; however, their focuses are not on the manufacturing. Ness et al. (2007) provided a categorization of sustainability assessment tools within a broader objective of lifting the understanding of sustainability assessment from a narrow, environmental focus to a wider interpretation of sustainability. Kinderyte (2008) presented comparison criteria of methodologies for corporate sustainability assessment. Baumann and Cowell (1999) suggested an evaluative framework for comparing conceptual and analytical approaches used in environmental management based on their methodological features. These research efforts defined their own schemes for classification with focus on environmental aspects of sustainability, not on MSA.

There also exist research efforts related to classification of sustainability assessment for the purpose of investigating existing research. They defined simple criteria to support their literature review. Pope et al. (2004) reviewed and categorized sustainability assessment approaches, and Hasna (2008) and Singh et al. (2012) reviewed sustainability assessment methods. Gunasekaran and Spalanzani (2012) reviewed and classified the literature available on Sustainable Business Development (SBD) in manufacturing and services. Finnveden and Moberg (2005) reviewed environmental systems analysis tools. Some criteria, which can be generally applied to sustainability assessment, are elicited from existing research efforts. The classification scheme proposed in this paper refers to those criteria to classify papers associated with MSA approaches.

\subsection{Defining Sustainable Manufacturing}

Sustainability has been interpreted in many ways based on requirements from different application domains and different objectives within those domains. One such domain is manufacturing, which can be considered as one of the most important domains for achieving the goal of sustainable development. Implementing sustainability in manufacturing will surely be one of the most positive contributions to sustainability in general (Rosen and Kishawy, 2012; Garetti and Taisch, 2012). For that reason, sustainable manufacturing has become more prominent in recent years. As with the preceding topics, there are a number of definitions of sustainability manufacturing. The US Department of Commerce defined that sustainable manufacturing is the creation of manufactured products that use processes that minimize negative environmental impacts, conserve energy and natural resources, are safe for employees, communities, and consumers and are economically sound (US DOC, 2009). The National Institute of Standards and Technology technically defined sustainable manufacturing as a systems approach for the creation and distribution (supply chain) of innovative products and services that: minimizes resources (inputs such as materials, energy, water, and land); eliminates toxic substances; and produces zero waste that in effect reduces greenhouse gases, e.g., carbon intensity, across the entire life cycle of products and services (Rachuri et al., 2010). According to the National Council for Advanced Manufacturing (NACFAM, 2009), sustainable manufacturing includes the manufacturing 
of "sustainable" products and the sustainable manufacturing of all products. The former includes manufacturing of renewable energy, energy efficiency, green building, and other green and social equity-related products, and the latter emphasizes the sustainable manufacturing of all products taking into account the full sustainability and total life cycle issues related to the products manufactured. The Organisation for Economic Co-operation and Development stated that sustainable manufacturing is all about minimizing the diverse business risks inherent in any manufacturing operation while maximizing the new opportunities that arise from improving your processes and products (OECD, 2011). And the general principle of sustainable manufacturing is to reduce the intensity of materials use, energy consumption, emissions, and the creation of unwanted by-products while maintaining, or improving, the value of products to society and to organizations (OECD, 2009). The Lowell Center for Sustainable Production defined that sustainable production is the creation of goods and services using processes and system that are: non-polluting, conserving of energy and natural resources, economically viable, safe and healthful for workers, communities, and consumers, and socially and creatively rewarding for all working people (LCSP, 1998). According to the Intelligent Manufacturing Systems (IMS, 2011), sustainable manufacturing aims at developing innovative methods, practices, and technologies in the manufacturing field for addressing world-wide shortages of resources, for mitigating excess environmental load and for enabling an environmentally benign life-cycle of products. The Institute of Manufacturing at University of Cambridge stated that "sustainable manufacturing is ... developing technologies to transform materials without emission of greenhouse gases, use of non-renewable or toxic materials, or generation of waste" (Allwood, 2005). The Sustainable Manufacturing Consulting defined sustainable manufacturing as a business practice of the industrial sector, which expands all the company's processes and decisions into the social and natural environments it operates in and affects, with the explicit objective of reducing or eliminating any negative impact, while pursuing the desired level of technological and economic performance (LeahuAluas, 2009-2010).

Despite various concepts of sustainable manufacturing, it is difficult to get practical understanding of the manufacturing sustainability and MSA concepts from them. That is because most sustainable manufacturing definitions are at a conceptual level and there exists significant difference between sustainable manufacturing and manufacturing sustainability. Generally speaking, sustainable manufacturing is a status that manufacturing is "sustainable"; in other words, sustainable manufacturing means that sustainability is already accomplished in manufacturing. The concept of sustainability in manufacturing is referred to as manufacturing sustainability in this paper. To determine whether or not the manufacturing is sustainable, it is required to assess its manufacturing sustainability. Section 3 addresses manufacturing sustainability and its assessment in more detail. 


\section{THE OPERATIONAL DEFINITIONS OF MANUFACTURING SUSTAINABILITY}

AND MANUFACTURING SUSTAINABILITY ASSESSMENT

It is clear from the preceding discussions, that there are no commonly agreed upon operational definitions of manufacturing sustainability and MSA. Since they are required for our research inventory framework, we now provide such definitions to ground the premise for our work.

\subsection{Requirements for Operational Definition}

An operational definition is a statement that describes how a particular variable is to be measured or how an object or condition is to be recognized (Prentice Hall, 2001). It defines something (e.g., a variable, term, or object) in terms of the specific process or set of validation tests used to determine its presence and quantity. That is, one defines something in terms of the operations that count as measuring it (Shoemaker et al., 2004; Wikipedia-Operational Definition, 2012). The requirements for an operational definition are that

- It has criteria or variables

- It has operations

- It must be measurable or observable

- It must be practical

It is important to set criteria or variables for a well-defined concept in an operational way. An operational definition translates the verbal concept into corresponding criteria or variables which can be measured. The concept can be referred to as a variable since it can respond to differences in the real world by taking on varying values, as specified in the operational definition (Watt and van den Berg, 1995). An operational definition contains one or more operations that measure the values of the criteria (Shoemaker et al., 2004; Wikipedia-Operational Definition, 2012). The most fundamental idea is that an operational definition must be measurable or observable. An operational definition aims to convert a concept into a measurement (Watt and van den Berg, 1995). More importantly, anyone can use the operations to repeat that measurement. It is this, in this sense, that an operational definition is practical. In summary then, an operational definition removes the ambiguity from a concept by actually measuring a variable related to that concept.

\subsection{Manufacturing Sustainability and Manufacturing Sustainability Assessment}

In this section, we provide operational definitions of manufacturing sustainability and MSA.

\subsubsection{Operational Definition for Manufacturing Sustainability}

Most existing definitions of sustainable manufacturing consider product, process, and system as main components (Jawahir, 2008; Jayal et al., 2010; ASME, 2011). We include these same concepts, called 
the MS's 3P, in our definition: product design, process plan, and production system. We define the scope of these components as follows. Product design is the detailed specification of a manufactured item's parts and their relationships to the whole (Product Design, 2012). Process plan is a collection of relational models of processes, equipment, tooling, and the sequencing of operations required to produce a product based on the product design. Production system consists of production resources that execute the processes contained in the process plan (Koho, 2010). Using this MS's 3P, our operational definition of manufacturing sustainability is:

Manufacturing sustainability is a measure of manufacturing performance metrics of product design, process plan, and production system with respect to environment, economy, and society, when executing a process plan for a product design in a given production system.

The operational aspect of this definition has to do with the measurement of the impacts on environment, economy, and society. Figure 3 depicts the interrelationships among manufacturing sustainability, the MS's 3P, and these impacts in order to understand manufacturing sustainability. In the following section, we address the assessment of these impacts.

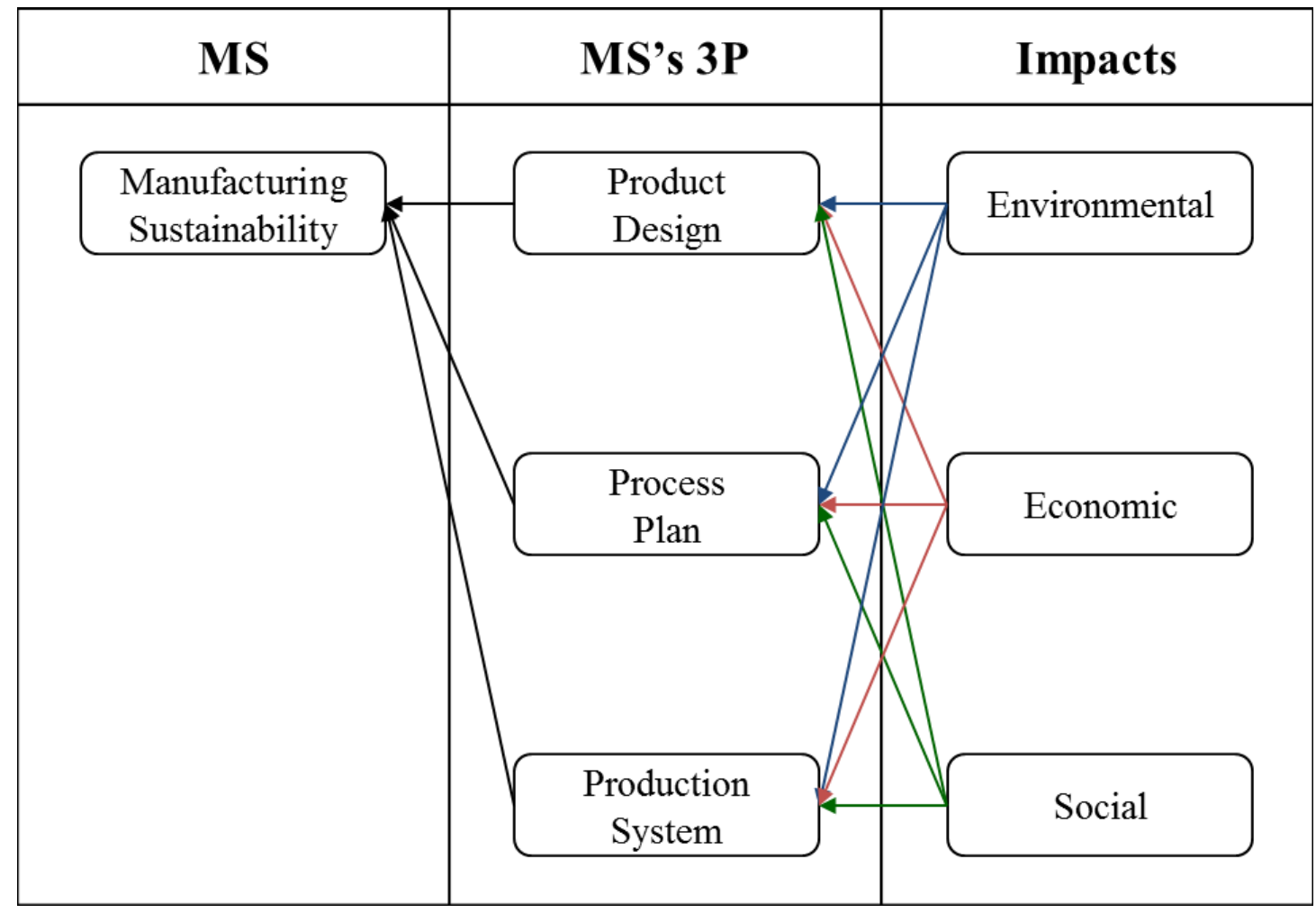

Figure 3. Interrelationships among manufacturing sustainability, the MS's 3P, and impacts 


\subsubsection{Operational Definition for Manufacturing Sustainability Assessment}

The definition of MSA is proposed based on the MS definition:

Manufacturing sustainability assessment is to determine a value of the manufacturing sustainability metric, which is a balanced performance of product design, process plan, and production system with respect to environmental, economic, and social aspects of sustainability.

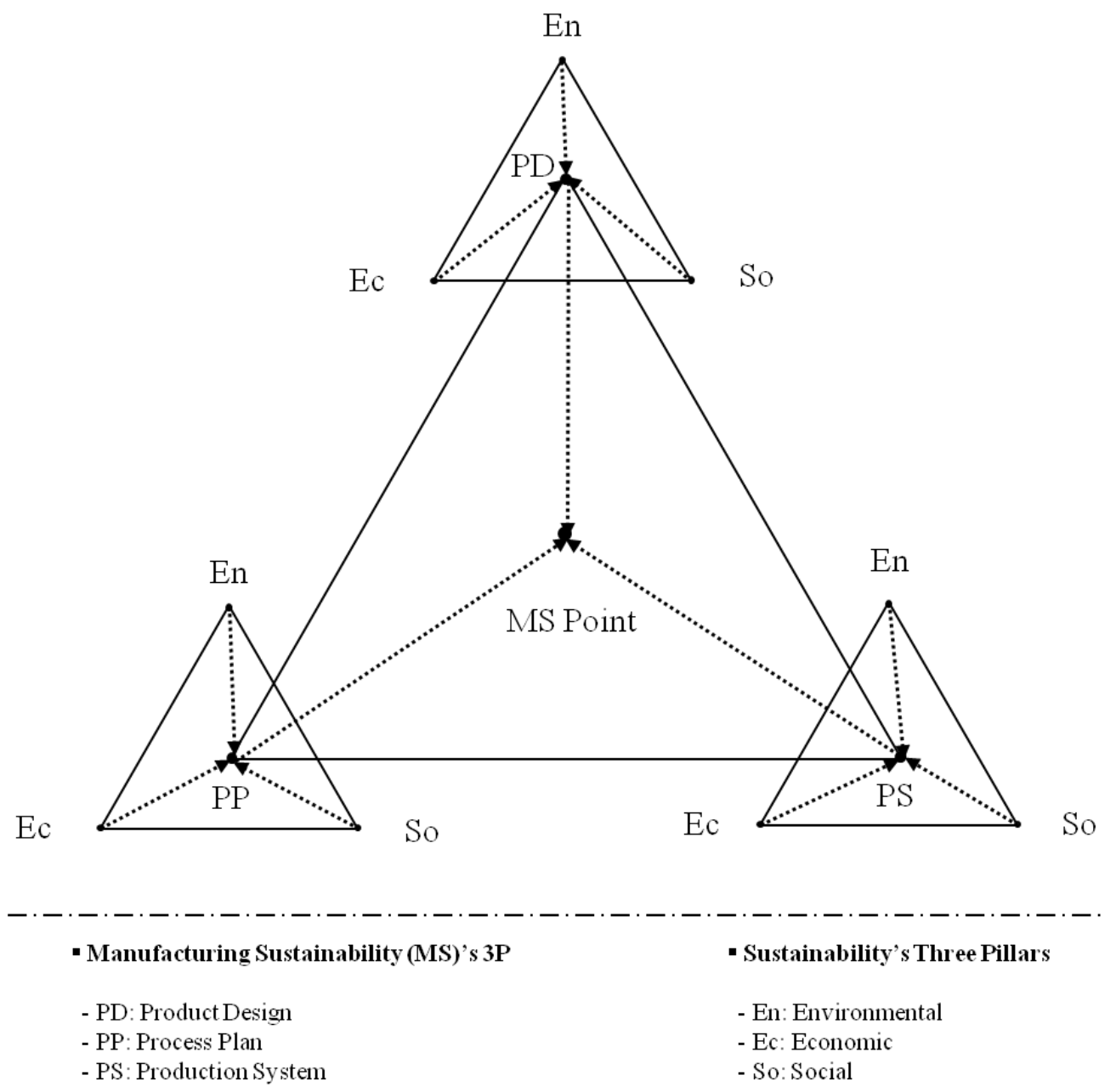

Figure 4. Definition of MSA

Figure 4 depicts the relationships among the MS's 3P (i.e., PD, PP, and PS) and three pillars of sustainability (i.e., En, Ec, and So) in an operational manner. Table 1 shows all of the potential impact assessments that can be performed. Each row depicts one of the MS's 3P and each column depicts one of the pillars. Additionally, the table shows aggregated rows ( $\left.\mathbf{P D}_{\mathrm{MS}}, \mathbf{P P}_{\mathbf{M S}}, \mathbf{P S}_{\mathrm{MS}}\right)$, aggregated columns $\left(\mathbf{E n}_{\text {Total }}, \mathbf{E c}_{\text {Total }}, \mathbf{S o}_{\text {Total }}\right)$ and a variable called $\mathbf{M S} \mathbf{S}_{\text {Point }}$ MS $\mathbf{M}_{\text {Point }}$ represents an aggregated balance among all of the impacts. This balance is achieved through a series of weights $\mathbf{W}_{\mathbf{S}}$. These weights can vary 
from one company to another.

Table 1. Various sustainability impacts explained with the MS's 3P and three pillars of sustainability

\begin{tabular}{cllll}
\hline & En & Ec & So & Total \\
\hline PD & $\mathrm{PD}_{\mathrm{En}}$ & $\mathrm{PD}_{\mathrm{Ec}}$ & $\mathrm{PD}_{\mathrm{So}}$ & PD $_{\mathrm{MS}}$ \\
$\mathbf{P P}$ & $\mathrm{PP}_{\mathrm{En}}$ & $\mathrm{PP}_{\mathrm{Ec}}$ & $\mathrm{PP}_{\mathrm{So}}$ & $\mathbf{P P}_{\mathrm{MS}}$ \\
$\mathbf{P S}$ & $\mathrm{PS}_{\mathrm{En}}$ & $\mathrm{PS}_{\mathrm{Ec}}$ & $\mathrm{PS}_{\mathrm{So}}$ & $\mathbf{P S}_{\mathrm{MS}}$ \\
Total & $\mathbf{E n}_{\text {Total }}$ & $\mathbf{E c}_{\text {Total }}$ & $\mathbf{S o}_{\text {Total }}$ & $\mathbf{M S}_{\text {Point }}$ \\
\hline
\end{tabular}

Computing the variables in the total column is usually quite difficult, since the metrics associated PD, PP, and PS are usually quite different. Thus, we can represent these computations formally as functions, $\mathbf{F}_{\mathbf{i}}$, as shown below.

$$
\begin{aligned}
& \mathbf{M S}_{\mathbf{P o i n t}}=\mathbf{F}\left(\boldsymbol{W}_{\boldsymbol{P D}} * \mathbf{P D}_{\mathrm{MS}}, \boldsymbol{W}_{\boldsymbol{P P} *} \mathbf{P P}_{\mathrm{MS}}, W_{P S^{*}} \mathbf{P S}_{\mathrm{MS}}\right) \\
& \mathbf{P D}_{\mathrm{MS}}=\mathrm{F}_{1}\left(W_{P D E n^{*}} \mathrm{PD}_{\mathrm{En}}, W_{P D E c^{*}} \mathrm{PD}_{\mathrm{Ec}}, W_{P D S o^{*}} \mathrm{PD}_{\mathrm{So}}\right) \\
& \mathbf{P P}_{\mathrm{MS}}=\mathrm{F}_{2}\left(W_{P P E n^{*}} \mathrm{PP}_{\mathrm{En}}, W_{P P E c^{*}} \mathrm{PP}_{\mathrm{Ec}}, W_{P P S o^{*}} \mathrm{PP}_{\mathrm{So}}\right) \\
& \mathbf{P S}_{\mathrm{MS}}=\mathrm{F}_{3}\left(W_{P S E n^{*}} * \mathrm{PS}_{\mathrm{En}}, W_{P S E c} * \mathrm{PS}_{\mathrm{Ec}}, W_{P S S o^{*}} \mathrm{PS}_{\mathrm{So}}\right)
\end{aligned}
$$

If the metrics can be converted and normalized to a single metric, such as cost, then the functions $\mathbf{F}_{\mathbf{i}}$, can be written as a weighted linear combination of the individual row values as shown below.

$$
\begin{aligned}
& \mathbf{M S}_{\mathbf{P o i n t}}=W_{P D^{*}} \mathbf{P D}_{\mathrm{MS}}+W_{P P^{*}} \mathbf{P P}_{\mathrm{MS}}+W_{P S^{*}} \mathbf{P S}_{\mathrm{MS}} \\
& \mathbf{P D}_{\mathrm{MS}}=W_{P D E n} * \mathrm{PD}_{\mathrm{En}}+W_{P D E c^{*}} \mathrm{PD}_{\mathrm{Ec}}+W_{P D S o^{*}} \mathrm{PD}_{\mathrm{So}} \\
& \mathbf{P P}_{\mathrm{MS}}=W_{P P E n *} \mathrm{PP}_{\mathrm{En}}+W_{P P E c} * \mathrm{PP}_{\mathrm{Ec}}+W_{P P S o *} \mathrm{PP}_{\mathrm{So}} \\
& \mathbf{P S}_{\mathrm{MS}}=W_{P S E n *} * \mathrm{PS}_{\mathrm{En}}+W_{P S E c^{*}} \mathrm{PS}_{\mathrm{Ec}}+W_{P S S o^{*}} \mathrm{PS}_{\mathrm{So}}
\end{aligned}
$$

Calculating the column values ( $\left.\mathbf{E n}_{\text {Total }}, \mathbf{E c}_{\text {Total }}, \mathbf{S o}_{\text {Total }}\right)$ will be conducted in the same way, if the values in each column have the same metric. They too can be calculated using a weighted linear combination of the individual column values as shown below.

$$
\begin{aligned}
& \mathbf{E n}_{\text {Total }}=W_{E n P D^{*}} \mathrm{PD}_{\mathrm{En}}+W_{E n P P *} \mathrm{PP}_{\mathrm{En}}+W_{E n P S^{*}} \mathrm{PS}_{\mathrm{En}} \\
& \mathbf{E c}_{\text {Total }}=W_{E c P D^{*}} \mathrm{PD}_{\mathrm{Ec}}+W_{E c P P *} \mathrm{PP}_{\mathrm{Ec}}+W_{E c P S^{*}} \mathrm{PS}_{\mathrm{Ec}} \\
& \mathbf{S o}_{\text {Total }}=W_{S o P D^{*}} \mathrm{PD}_{\mathrm{So}}+W_{S o P P *} \mathrm{PP}_{\mathrm{So}}+W_{S o P S^{*}} \mathrm{PS}_{\mathrm{So}}
\end{aligned}
$$

Note, as before, there is no simple formula for computing $\mathbf{M S}_{\mathbf{P o i n t}_{\mathrm{t}}}$ using $\mathbf{P D}_{\mathbf{M S}}, \mathbf{P P}_{\mathbf{M S}}$, and $\mathbf{P} \mathbf{S}_{\mathbf{M S}}$. 


\section{CLASSIFICATION SCHEME FOR MANUFACTURING SUSTAINABILITY ASSESSMENT APPROACH}

A classification scheme is required to establish the fundamental structure for research inventory of papers associated with MSA approaches. This paper presents a set of requirements for the classification scheme. The scheme to classify the MSA approaches is developed based on the requirements and definition of MSA in section 3. This section presents the requirements, the scheme, and the notation of the proposed classification. An implementation of the classification scheme is demonstrated through using an existing approach of MSA.

\subsection{Requirements for Classification Scheme}

5W1H, which stands for Why, Who, When, Where, What, and How, has been broadly employed in journalism to gather information (Chung et al., 2009). 5W1H can be used also to classify and navigate information with intuitive classification axes and retrieval keys (Ikeda et al., 1998). Hong and Davison (2009) used 5W1H as a classification method for their experiment on question answering in discussion boards. Huang et al. (2011) proposed a scheme based on the context of 5W1H in ubiquitous computing to establish a database for environmental monitoring factors. Ikeda et al. (1998) proposed a method by which $5 \mathrm{WlH}$ information is used to classify and navigate Japanese language texts.

We will use $5 \mathrm{~W} 1 \mathrm{H}$ to establish a set of requirements for classifying MSA approaches. How we use them is shown below.

- What: What aspects or facets of manufacturing sustainability does it assess?

- When: When is it needed to assess manufacturing sustainability?

- Where: Where is the scope targeted for assessing manufacturing sustainability?

- Who: Who has interest in assessing manufacturing sustainability?

- Why: Why does it assess manufacturing sustainability?

- How: How does it assess manufacturing sustainability?

What aspects or facets of manufacturing sustainability does it assess? This question is related to the contents, which are assessed by the approach in terms of manufacturing sustainability (Singh et al., 2012). When is it needed to assess manufacturing sustainability? It asks about a particular situation or purpose, which needs MSA. Where is the scope targeted for assessing manufacturing sustainability? It is literally about the scope of assessment (Ness et al., 2007). Defining a specific scope is important to classify the approaches for MSA. Who has interest in assessing manufacturing sustainability? This question can be interpreted as an interest unit of a stakeholder in manufacturing from an organizational perspective. Why does it assess manufacturing sustainability? It is about the purpose of 
MSA. How does it assess manufacturing sustainability? This question asks about the method of MSA (Hasna, 2008; Singh et al., 2012).

\subsection{Proposed Classification Scheme}

Figure 5 shows the 5-level, proposed classification scheme. Level 0 is the top level. It uses our operational definition of MSA to determine whether or not a paper is eligible to be included in the inventory. Level 1,2 , and 3 are criteria to define a generic classification scheme, and level 4 is categorical variables specialized from the generic criteria for the MSA approaches. Note, that this classification is meant to provide a list of potential key-words, in a prescribed order, that can be used to classify papers for retrieval.

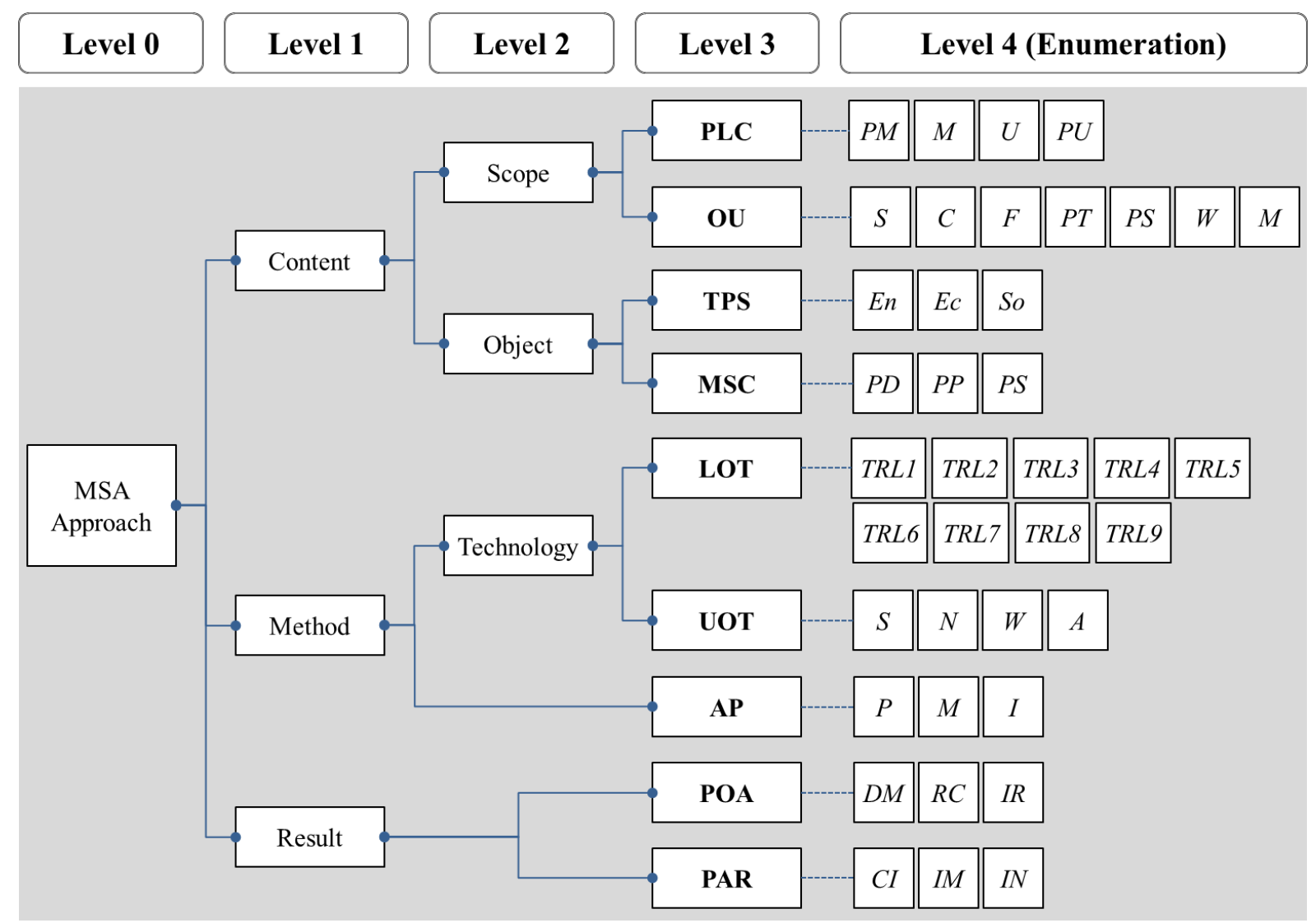

Figure 5. 5-level classification scheme for the MSA approaches

\section{Level 1, Level 2, and Level 3}

Level 1 comprises three criteria: content, method, and result. Content is formed from the 'what', 'where', and 'who' questions. The answers to these questions fall into two categories: scope and object. Scope is the boundary covered or targeted by the paper and has two sub criteria: Product Life Cycle (PLC) and Organizational Unit (OU). PLC identifies the product-life-cycle stage and $O U$ 
identifies the organizational unit level the paper addresses. Object identifies the sustainability areas assessed by the paper; it has two sub criteria: Three Pillars of Sustainability (TPS) and Manufacturing Sustainability Components (MSC). TPS is about three pillars of sustainability that are essential to assess manufacturing sustainability according to the proposed MSA definition. MSC refers to the MS's 3P, which is proposed as components of manufacturing sustainability in the proposed definition.

Method is about technical features of the MSA approach and is based on answers to the 'how' question. Method has two sub criteria: technology and Assessment Process (AP). Technology has two sub-criteria: Level Of Technology (LOT) and Use Of Technology (UOT). LOT identifies the maturity level of the paper's particular approach in terms of technology and UOT provides information on the type of technology used for the assessment. AP is related to the business process used to assess manufacturing sustainability. In order to operationally understand the MSA approach, it is required to know which step in the business process the approach can cover.

Result is formed from answers to the 'why' and 'when' questions; it has two sub criteria: Purpose Of Assessment (POA) and Presentation Of Assessment result (PAR). POA and PAR identify the purpose and the desired result type of the MAS approach respectively.

\section{Level 4}

All of the subcategories described above combine to form level 3 in the classification. These subcategories can be treated as categorical variables, which are referred to as enumerations at level 4 . Each categorical variable contains a set of possible values that might be defined based on consensus or common understanding. In this paper, values of the categorical variables are assigned based on the proposed MSA definition and a comprehensive study of MSA.

The categorical variables of $P L C$ correspond to the various stages of the life cycle. They are PreManufacturing (PM), Manufacturing (M), Use (U), or Post-Use (PU) (Jaafar et al., 2007). PM usually includes raw material extraction and processing; $P U$ is mainly related to disposal. The categorical variables of $O U$ include Supply chain (S), Company (C), Factory (F), ProducT (PT), ProcesS (PS), Work cell (W), or Machine tool (M) (Feng et al., 2010; Reich-Weiser et al., 2008). The categorical variables of TPS and MSC in the object criterion refer to the proposed MSA definition. TPS is Environmental (En), Economic (Ec), or Social (So), and MSC is Product Design (PD), Process Plan (PP), or Production System (PS).

The categorical variables of LOT refer to the Technology Readiness Levels (TRL), (TRL1,..., TRL9) (US DoD, 2011). TRL is a general measure to assess the maturity of evolving technologies even though TRL levels are not specialized for the technology for sustainability assessment (Wikipedia-TRL, 2012). The variables of UOT are related to Scaling (S), Normalization (N), Weighting (W), or Aggregation (A) (Singh et al., 2012). The AP variables refer to the OECD 
Sustainable Manufacturing Toolkit, which defines 3 main steps: Prepare $(P)$, Measure $(M)$, and Improve (I) (OECD, 2011).

The categorical variables of POA take in values associated with Decision-Making (DM), Reporting/Communication (RC), or Identifying/Ranking (IR). Eventually, the results of any MSA are used to support some kind of a decision-making process. As a result, many papers are expected to be about decision making. Frequently, the results of an assessment or decision must be communicated and forwarded to another entity. The Global Reporting Initiative (GRI, 2010-2011) provides a set of protocols for this purpose. Sustainability assessment can also be used for identifying or ranking the level of sustainability against a predetermined set of benchmarks (Kinderytė, 2008; Baumann and Cowell, 1999). The categorical variables of PAR are Composite Index (CI), IMpact (IM), or INdicator (IN) (Kinderyte், 2008). The sustainability indicator values are directly calculated by sustainability metrics while the impact values are determined based on the sustainability indicator values. The composite index is an aggregated total score of manufacturing sustainability based on sustainability indicator or impact values.

\subsection{Notation for Classification Scheme}

The proposed classification scheme will provide the fundamental structure of our research inventory. That is, it will provide the basis for storing and retrieving papers from the inventory. This section proposes a math-based notation to express the classification information for this purpose. Assume that $\mathbf{C}$ is a nonempty finite set of criteria in the classification scheme. $\mathbf{C}_{\mathbf{i}}$ and $\mathbf{C}_{\mathbf{j}}$ are sets of $\mathbf{i}$ and $\mathbf{j}$ respectively, which are criteria in the classification scheme. The relationships among all sets can then be represented as equations from $\mathbf{N} 1$ to $\mathbf{N} 2$.

The top level criteria, $\mathbf{C}_{\mathbf{M S A}}$, can be represented as a union set of 3 union sets that exist at level 1. Each set of content, method, and result is expressed by a union set of union sets or sets of their elements. For example, $\mathbf{C}_{\text {content }}$ is a union set of $\mathbf{C}_{\text {Scope }}$ and $\mathbf{C}_{\text {Object }}$ where $\mathbf{C}_{\text {Scope }}$ is a union set of $\mathbf{C}_{\mathbf{P L C}}$ and $\mathbf{C}_{\text {OU }}$, and $\mathbf{C}_{\text {Object }}$ is a union set of $\mathbf{C}_{\text {TPS }}$ and $\mathbf{C}_{\text {MSC }}$. Each set of PLC, OU, TPS, MSC, LOT, UOT, $\boldsymbol{A P}, \boldsymbol{P O A}$, and $\boldsymbol{P A R}$ can be represented by the elements of their categorical variables.

$$
\begin{aligned}
& \mathbf{C}_{\text {MSA }}=\mathbf{C}_{\text {Content }} \cup \mathbf{C}_{\text {Method }} \cup \mathbf{C}_{\text {Result }}=\left\{\mathbf{c} \mid \mathbf{c} \in \mathbf{C}_{\text {Content }} \vee \mathbf{C}_{\text {Method }} \vee \mathbf{C}_{\text {Result }}\right\} \\
& \text { where, } C_{i} \cap C_{j}=\varnothing\left\{i \neq j \wedge C_{i}, C_{j} \in\left\{C_{\text {Content }}, C_{\text {Method }}, C_{\text {Result }}\right\}\right\} \\
& \mathbf{C}_{\text {Content }}=\mathbf{C}_{\text {Scope }} \cup \mathbf{C}_{\text {Object }}=\left\{\mathbf{c} \mid \mathbf{c} \in \mathbf{C}_{\text {Scope }} \vee \mathbf{C}_{\text {Object }}\right\} \\
& \text { where, } C_{i} \cap C_{j}=\varnothing\left\{i \neq j \wedge C_{i}, C_{j} \in\left\{C_{\text {Scope }}, C_{\text {Object }}\right\}\right\} \\
& \mathbf{C}_{\text {Sope }}=\mathbf{C}_{\text {PLC }} \cup \mathbf{C}_{\text {OU }}=\left\{\mathbf{c} \mid \mathbf{c} \in \mathbf{C}_{\text {PLC }} \vee C_{\text {OU }}\right\} \\
& \text { where, } C_{i} \cap C_{j}=\varnothing\left\{i \neq j \wedge C_{i}, C_{j} \in\left\{C_{\text {PLC }}, C_{\text {OU }}\right\}\right\}
\end{aligned}
$$




$$
\begin{aligned}
& \mathrm{C}_{\text {Object }}=\mathrm{C}_{\mathrm{TPS}} \cup \mathrm{C}_{\mathrm{MSC}}=\left\{\mathbf{c} \mid \mathbf{c} \in \mathrm{C}_{\mathrm{TPS}} \vee \mathrm{C}_{\mathrm{MSC}}\right\} \\
& \text { where, } \mathrm{C}_{\mathrm{i}} \cap \mathrm{C}_{\mathrm{j}}=\varnothing\left\{\mathrm{i} \neq \mathrm{j} \wedge \mathrm{C}_{\mathrm{i}}, \mathrm{C}_{\mathrm{j}} \in\left\{\mathrm{C}_{\mathrm{TPS}}, \mathrm{C}_{\mathrm{MSC}}\right\}\right\} \\
& \mathrm{C}_{\text {Method }}=\mathrm{C}_{\text {Technology }} \cup \mathrm{C}_{\mathrm{AP}}=\left\{\mathbf{c} \mid \mathbf{c} \in \mathrm{C}_{\text {Technology }} \mathrm{C}_{\mathrm{AP}}\right\} \\
& \text { where, } C_{i} \cap C_{j}=\varnothing\left\{i \neq j \wedge C_{i}, C_{j} \in\left\{C_{\text {Technology }}, C_{A P}\right\}\right\} \\
& \mathrm{C}_{\mathrm{Technology}}=\mathrm{C}_{\mathrm{LOT}} \cup \mathrm{C}_{\mathrm{UOT}}=\left\{\mathrm{c} \mid \mathrm{c} \in \mathrm{C}_{\mathrm{LOT}} \vee \mathrm{C}_{\mathrm{UOT}}\right\} \\
& \text { where, } \mathrm{C}_{\mathrm{i}} \cap \mathrm{C}_{\mathrm{j}}=\emptyset\left\{\mathrm{i} \neq \mathrm{j} \wedge \mathrm{C}_{\mathrm{i}}, \mathrm{C}_{\mathrm{j}} \in\left\{\mathrm{C}_{\mathrm{LOT}}, \mathrm{C}_{\mathrm{UOT}}\right\}\right\} \\
& \mathbf{C}_{\text {Result }}=\mathbf{C}_{\mathbf{P O A}} \cup \mathbf{C}_{\mathbf{P A R}}=\left\{\mathbf{c} \mid \mathbf{c} \in \mathbf{C}_{\mathbf{P O A}} \vee \mathbf{C}_{\mathbf{P A R}}\right\} \\
& \text { where, } C_{i} \cap C_{j}=\emptyset\left\{i \neq j \wedge C_{i}, C_{j} \in\left\{C_{P O A}, C_{P A R}\right\}\right\} \\
& \mathbf{C}_{\mathbf{M S A}}=\left\{\left\{\left\{\mathbf{C}_{\mathbf{P L C}} \vee \mathbf{C}_{\mathbf{O U}}\right\} \vee\left\{\mathbf{C}_{\mathbf{T P S}} \vee \mathbf{C}_{\mathbf{M S C}}\right\}\right\} \vee\left\{\left\{\mathbf{C}_{\mathbf{L O T}} \vee \mathbf{C}_{\text {UOT }}\right\} \vee \mathbf{C}_{\text {AP }}\right\} \vee\left\{\mathbf{C}_{\mathbf{P O A}} \vee \mathbf{C}_{\mathbf{P A R}}\right\}\right\} \\
& \mathrm{C}_{\mathrm{OU}}=\{\mathrm{S}, \mathrm{C}, \mathrm{F}, \mathrm{PT}, \mathrm{PS}, \mathrm{W}, \mathrm{M}\} \\
& \mathbf{C}_{\mathrm{TPS}}=\{\text { En, Ec, So }\} \\
& \mathrm{C}_{\mathrm{MSC}}=\{\mathrm{PD}, \mathrm{PP}, \mathrm{PS}\} \\
& \mathbf{C}_{\text {LOT }}=\{\text { TRL1, TRL2, TRL3, TRL4, TRL5, TRL6, TRL7, TRL8, TRL9 }\} \\
& \mathrm{C}_{\mathrm{UOT}}=\{\mathrm{S}, \mathrm{N}, \mathrm{W}, \mathrm{A}\} \\
& \mathrm{C}_{\mathrm{AP}}=\{\mathrm{P}, \mathrm{M}, \mathrm{I}\} \\
& \mathrm{C}_{\mathrm{POA}}=\{\mathrm{DM}, \mathrm{RC}, \mathrm{IR}\} \\
& \mathrm{C}_{\mathrm{PAR}}=\{\mathrm{CI}, \mathrm{IM}, \mathrm{IN}\}
\end{aligned}
$$

\subsection{Demonstration of the Proposed Classification Scheme}

In this section, we demonstrate how to use the proposed classification scheme and its notation on a paper entitled, "The OECD Sustainable Manufacturing Toolkit." This paper provides a set of internationally applicable, common, and comparable indicators to measure the environmental performance of manufacturing facilities of any size and in any sector or country (OECD, 2011). This paper was analyzed using the feature analysis method and its meta-information was expressed using our classification scheme.

The feature analysis method is the most prominent and popular comparison/evaluation approach that has been used. In its screening mode, it can be performed by a single person who is responsible for both generating the evaluation criteria and assessing the methodologies. The evaluation is solely based on his/her understanding of the methodologies according to their documentation (Dam, 2003). 
Figure 6 shows the results of the features analysis method applied to the OECD paper. The values in the various cells are explained as follows (OECD, 2011):

- PLC. The OECD toolkit covers the manufacturing (M) and use (U) stages of product life cycle. The toolkit mainly focuses on the manufacturing stage, but it also considers energy consumption and greenhouse gas emissions from the use of the manufactured products. Therefore, $\mathrm{C}_{\mathrm{PLC}}$ of the OECD toolkit is represented as $\{\mathrm{M}, \mathrm{U}\}$.

- $\boldsymbol{O U}$. The indicators in the toolkit have been developed for the production activities of a single facility. That is, the OECD toolkit covers from work cell (W), through process (PS) and product (PT), to factory (F) levels. The toolkit additionally explains that the toolkit's coverage can be extended to include the boundary to company (C) and supply chains (S). However, OECD indicators do not cover detailed sustainability data at the machine tool (M) level. Thus, $\mathrm{C}_{\mathrm{OU}}$ is represented as $\{\mathrm{S}, \mathrm{C}, \mathrm{F}, \mathrm{PT}, \mathrm{PS}, \mathrm{W}\}$.

- TPS. Since the toolkit considers only the environmental aspect (En) of sustainability, $\mathrm{C}_{\mathrm{TPS}}$ of the OECD toolkit is represented as $\{$ En $\}$.

- MSC. The toolkit considers production system (PS) as well as product (PD) and production process $(\mathrm{PP})$. Some indicators on operations, such as water or energy intensity, are calculated based on the data of production process and overhead at the facility level. Therefore, $\mathrm{C}_{\mathrm{MSC}}$ is represented as $\{\mathrm{PD}, \mathrm{PP}, \mathrm{PS}\}$.

- LOT. The technical level of the OECD toolkit is at TRL8 that is determined based on the current status: it was internationally published by OECD; it supports a guide document and web portal; but it still cannot fully support its desired goal and certain functions. $\mathrm{C}_{\mathrm{LOT}}$ of the OECD toolkit is represented as \{TRL8\}.

- UOT. The toolkit explains how to measure $(\mathrm{S})$ and normalize $(\mathrm{N})$ its indicators, and what data is needed for those processes. Thus, $\mathrm{C}_{\mathrm{UOT}}$ is represented as $\{\mathrm{S}, \mathrm{N}\}$.

- $\boldsymbol{A P}$. The OECD toolkit presents 7 steps, which are categorized into 3 main steps: prepare $(\mathrm{P})$, measure (M), and improve (I). The guide provides the detailed explanation about each step of the toolkit. Thus, $\mathrm{C}_{\mathrm{AP}}$ of the OECD toolkit is represented as $\{\mathrm{P}, \mathrm{M}, \mathrm{I}\}$.

- POA. The indicators addressed in the toolkit mainly assist decision-making (DM) and internal management including reporting/communication (RC). It is possible to compare or rank (IR) the targets through a normalization factor. $\mathrm{C}_{\mathrm{POA}}$ is represented as $\{\mathrm{DM}, \mathrm{RC}, \mathrm{IR}\}$.

- PAR. The OECD toolkit is mainly composed of its own indicators. The results are provided with each value of indicators (IN) separately. The guide explains the way to analyze cost and benefits in terms of improvement, but not about a composite index (CI) or values of impacts (IM). Thus, $\mathrm{C}_{\mathrm{PAR}}$ is represented as $\{\mathrm{IN}\}$. 


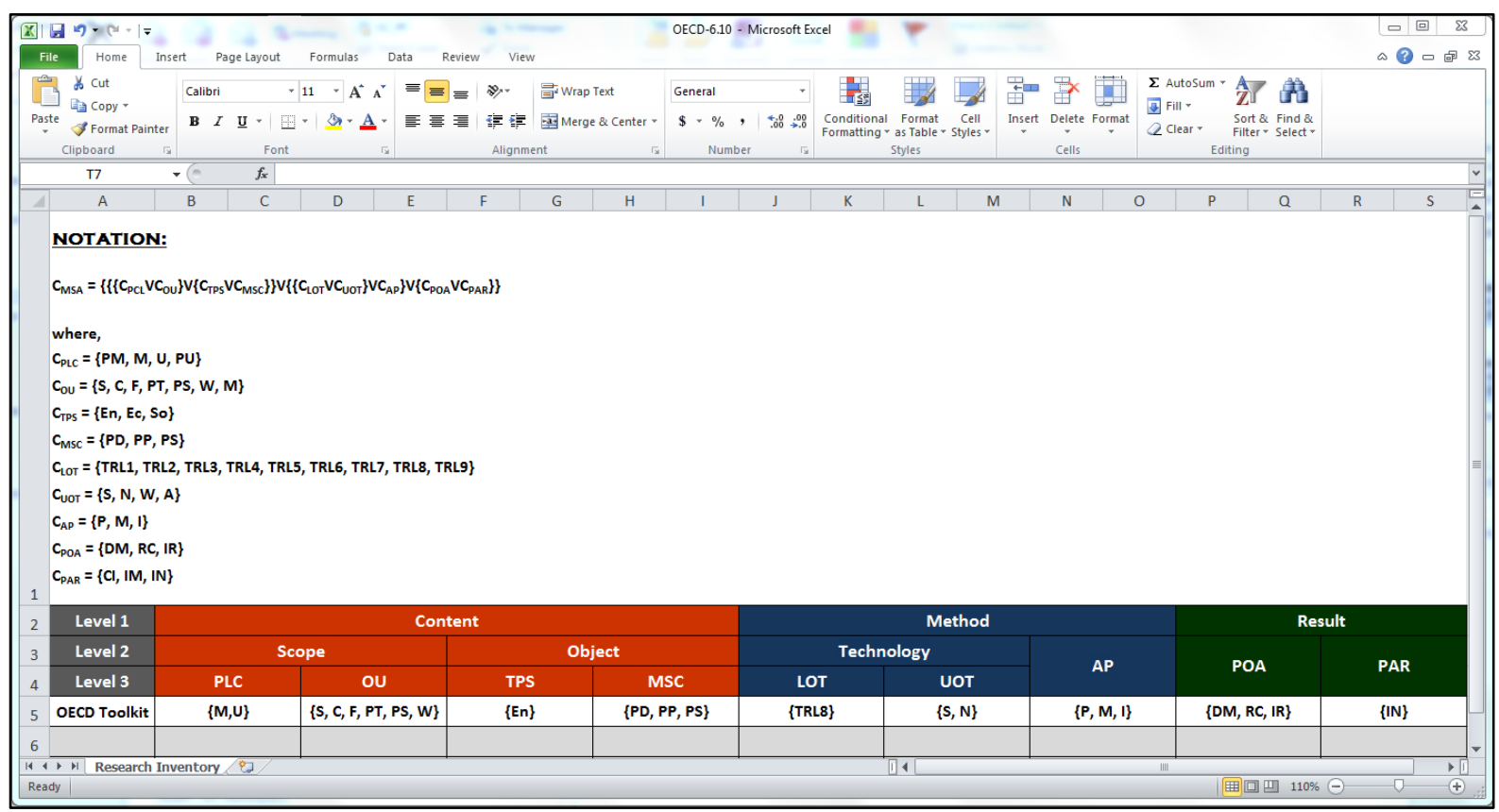

Figure 6. Implementation of OECD Sustainable Manufacturing Toolkit in research inventory

In summary on this application, it was possible to express important meta-information of the OECD Sustainable Manufacturing Toolkit with the scheme proposed for classifying the MSA approaches. The classification result could be easily implemented into the research inventory using the notation presented in section 4.3.

\section{CONCLUSION}

This paper has presented a framework for a research inventory containing papers related to MSA. The proposed framework primarily consists of two parts: an operational definition of MSA and a scheme to classify the related papers. The operational definitions of manufacturing sustainability and MSA were proposed in consideration of the requirements defined for an operational definition. This paper has suggested the classification scheme based on its requirements stated by $5 \mathrm{~W} 1 \mathrm{H}$. In addition, the notation was defined to represent the classification information in a systematic and computational way for retrieving, understanding, and using papers from the inventory. Lastly, the classification scheme was demonstrated by applying it to the existing approach, the OECD Sustainable Manufacturing Toolkit.

The framework proposed in this paper provides conceptual and structural foundations of the research inventory of papers that describe various MSA approaches. Such a research inventory would 1) make research papers accessible and available, 2) provide a general understanding of research papers, 3) investigate the state of the art of research papers, and 4) identify gaps and recommend a research roadmap. Eventually, this inventory enables manufacturing industries to improve the 
sustainability of their manufacturing processes by leveraging appropriate MSA approaches provided by the inventory.

This paper includes information that can adequately represent the approaches of MSA in the classification scheme. In that sense, criteria in the scheme are focused on specific features of the MSA approaches. The classification scheme can be improved by including more general attributes on the approaches (e.g., data availability or flexibility) in the future.

\section{ACKNOWLEDGMENT}

The authors like to thank Swee Leong and Prof. Chin-Sheng Chen. They provided valuable inputs and recommendations on this paper. Special thanks go to Dr. Albert Jones for his support and technical lead.

\section{REFERENCES}

American Society of Mechanical Engineers (ASME), 2011. ASME Sustainable Products and Processes Strategic Plan [online]. Available from: http://files.asme.org/Committees/K\&C/ TCOB/CRTD/30032.pdf [Accessed 10 November 2012].

Allwood, J., 2005. What is Sustainable Manufacturing? Sustainable Manufacturing Seminar Series, Institute of Manufacturing, University of Cambridge [online]. Available from: http://www.ifm.eng.cam.ac.uk/ [Accessed 26 August 2013].

Approach [online]. Available from: http://dictionary.reference.com/browse/approach [Accessed 29 November 2012].

Baumann, H., Cowell, S.J., 1999. An evaluative framework for conceptual and analytical approaches used in environmental management. Greener Management International: The Journal of Corporate Environmental Strategy and Practice, 26, 109-122.

Baumgartner, R.J., 2011. Critical perspectives of sustainable development research and practice. Journal of Cleaner Production, 19(8), 783-786.

Beloff, B., Tanzil, D., Lines, M., 2004. Sustainable development performance assessment. Environmental Progress, 23(4), 271-276.

Brundtland Commission, 1987. Our Common Future-From One Earth to One World. Oxford University Press, Oxford, England.

Buselich, K., 2002. An Outline of Current Thinking on Sustainability Assessment. Background paper prepared for the Western Australian State Sustainability Strategy. Institute for Sustainability and Technology Policy, Murdoch University, Western Australia.

Chung, S., Won, D., Baeg, S.H., Park, S., 2009. Service-oriented reverse reengineering: 5W1H model-driven re-documentation and candidate services identification. Proceedings of IEEE International Conference on Service-Oriented Computing and Applications (SOCA), 1-6, Taipei, 
Taiwan.

Dam K.H., 2003. Evaluating and Comparing Agent-Oriented Software Engineering Methodologies. Master Thesis of Applied Science in Information Technology. School of Computer Science and Information Technology of RMIT University, Australia.

Devuyst, D., Hens, N., 2001. How Green is the City? Sustainability assessment and the management of urban environments. Columbia University Press, New York.

Do, N.C., 2010. The Definition of Sustainable Manufacturing. KEDM PLM [online]. Available from: http://fvortal.cimerr.net/plm/122?category=26 [Accessed 28 August 2013].

Earth Charter Initiative, 2000. The Earth Charter [online]. Available from: http://www.earthcharterinaction.org/content/pages/Read-the-Charter.html [Accessed 3 July 2012].

Ecologically Sustainable Development Steering Committee, 1992. National Strategy for Ecologically Sustainable Development [online]. Available from: http://www.environment.gov.au/about/esd/ publications/strategy/index.html [Accessed 12 October 2012].

European Science Foundation (ESF), 2013. The MERIL portal [online]. Available from: http://portal.meril.eu/converis-esf/publicweb/startpage [Accessed 27 January 2013].

Feng, S.C., Joung, C.B., Li, G., 2010. Development Overview of Sustainable Manufacturing Metrics. Proceedings of the 17th CIRP International Conference on Life Cycle Engineering.

Finnveden, G., Moberg, A., 2005. Environmental systems analysis tools - an overview. Journal of Cleaner Production, 13(12), 1165-1173.

Forestry Commission of Great Britain, Sustainability [online]. Available from: http://www.forestry.gov.uk/forestry/edik-59fmzf [Accessed 5 September 2012].

Garetti, M., Taisch, M., 2012. Sustainable manufacturing: Trends and research challenges. Production Planning \& Control, 23 (2-3), 83-104.

Glavic, P., Lukman, R., 2007. Review of sustainability terms and their definitions. Journal of Cleaner Production, 15(18),1875-1885.

Global Reporting Initiative (GRI), 2010-2011. Sustainability Reporting Guidelines Version 3.1 [online]. Available from: http://www.globalreporting.org [Accessed 28 August 2013].

Gunasekaran, A., Spalanzani, A., 2012. Sustainability of manufacturing and services: Investigations for research and applications. International Journal of Production Economics, 140(1), 35-47.

Hardcastle, A., Waterman-Hoey, S., 2010. Advanced Materials Manufacturing, Sustainability and Workforce Development. Washington State University Extension Energy Program [online]. Available from: http://www.energy.wsu.edu/ [Accessed 28 October 2012].

Hasna, A.M., 2008. A review of sustainability assessment methods in engineering. The International Journal of Environmental, Cultural, Economic \& Social Sustainability, 5(1), 161-176.

Hediger, W., 2000. Sustainable development and social welfare. Ecological Economics, 32(3), 481- 
492.

Hong, L., Davison, B.D., 2009. A Classification-based Approach to Question Answering in Discussion Boards. Proceedings of ACM SIGIR conference on Research and development in information retrieval, 171-178. New York, USA.

Huang, Y.P., Chang, H.C., Lin, C.C., 2011. Systematic design of environmental monitoring interface by Bayesian classification. Proceedings of 2011 International Conference on System Science and Engineering, 43-48, Macau, China.

Ikeda, T., Okumura, A., Muraki, K., 1998. Information Classification and Navigation Based on 5W1H of the Target Information. Proceedings of the 17th International Conference on Computational Linguistics, 1, 571-577, Montreal, Quebec, Canada.

Intelligent Manufacturing Systems (IMS), 2011. Maintenance for Sustainable Manufacturing (M4SM), White paper of the IMS M4SM MTP initiative [online]. Available from: http://www.ims.org/ [Accessed 10 October 2012].

International Society for the Psychoanalytic Study of Organizations (ISPSO), 2012. ISPSO Research Inventory [online]. Available from: http://www.ispso.org/the-field:research-projects [Accessed 6 January 2013].

Jaafar, I.H., Venkatachalam, A., Joshi, K., Ungureanu, A.C., De Silva, N., Dillon Jr, O.W., Rouch, K.E., Jawahir, I.S., 2007. Product Design for Sustainability: A New Assessment Methodology and Case Studies. In Environmentally Conscious Mechanical Design (Ed M. Kutz), John Wiley \& Sons, Inc., 25-65, NJ, USA.

Jayal, A.D., Badurdeen, F., Dillon, O.W., Jawahir, I.S., 2010. Sustainable manufacturing: Modeling and optimization challenges at the product, process and system levels. CIRP Journal of Manufacturing Science and Technology, 2(3), 144-152.

Jawahir, I.S., 2008. Beyond the 3R's: 6R Concepts for Next Generation Manufacturing: Recent Trends and Case Studies. Symposium on Sustainability and Product Development, IIT, Chicago, USA [online]. Available from: http://mmae.iit.edu/symposium/downloads/pres/Jawahir.pdf [Accessed 17 February 2012].

Kinderyte, L., 2008. Analysis and Comparison of Methodologies for Corporate Sustainability Assessment. Environmental Research, Engineering and Management, 4(46), 66-75.

Koho, M., 2010. Production system assessment and improvement: a tool for make-to-order and assemble to-order companies. Doctoral dissertation, Tempere University of Technology (TUT), Publication 885.

Labuschagne, C., Brent, A.C., 2005. Sustainable project life cycle management: the need to integrate life cycles in the manufacturing sector. International Journal of Project Management 2005, 23(2), 159-168. 
Leahu-Aluas, S., 2009-2010. Sustainable Manufacturing: An Overview for Manufacturing Engineers. Sustainable Manufacturing consulting [online], Available from: http://sustainablemanufacturing.biz/ [Accessed 29 August 2013].

Lowell Center for Sustainable Production (LCSP), 1998. What is Sustainable Production? [online]. Available from: http://www.sustainableproduction.org/abou.what.php [Accessed 22 May 2012].

Lozano, R., 2008. Envisioning sustainability three-dimensionally. Journal of Cleaner Production, 16(17), 1838-1846.

Manufacturing Skills Australia (MSA), 2008. Sustainable manufacturing - Manufacturing for sustainability [online]. Available from: http://www.mskills.com.au/ShopProduct.aspx?pid=42 [Accessed 10 September 2012].

National Council for Advanced Manufacturing (NACFAM), 2009. Sustainable Manufacturing [online]. Available from: http://www.nacfam.org/Default.aspx [Accessed 28 August 2013].

Ness, B., Urbel-Piirsalu, E., Anderberg, S., Olsson, L., 2007. Categorising tools for sustainability assessment. Ecological Economics, 60(3), 498-508.

Organisation for Economic Co-operation and Development (OECD), 2009. Overview of the OECD Sustainable Manufacturing Toolkit Prototype [online]. Available from: http://www.oecd.org/industry/industryandglobalisation/44280332.pdf [Accessed 4 July 2012].

Organisation for Economic Co-operation and Development (OECD), 2011. OECD Sustainable Manufacturing Toolkit [online]. Available from: http://www.oecd.org/innovation/green/toolkit/ [Accessed 15 August 2012].

Patient-Centered Outcomes Research Institute (PCORI), 2012. Comprehensive Inventory of Research Networks [online]. Available from: http://www.pcori.org/ [Accessed 9 February 2013].

Pope, J., Annandale, D., Morrison-Saunders, A., 2004. Conceptualising Sustainability Assessment. Environmental Impact Assessment Review, 24(6), 595-616.

Prentice Hall, 2001. Prentice Hall Science Explorer Inquiry Skills Activity Book. Prentice Hall, California.

Product Design [online]. Available from: http://www.businessdictionary.com/definition/productdesign [Accessed 20 November 2012].

Rachuri, S., Sriram, R.D., Narayanan, A., Sarkar, P., Lee, J.H., Lyons, K.W., Kemmerer, S.J., 2010. Sustainable Manufacturing: Metrics, Standards, and Infrastructure. Workshop Report of National Institute of Standards and Technology, NISTIR 7683.

Reich-Weiser, C., Vijayaraghavan, A., Dornfeld, D.A., 2008. Metrics for Sustainable Manufacturing. Proceedings of the 2008 International Manufacturing Science and Engineering Conference, Illinois, USA.

Rosen, M.A., Kishawy, H.A., 2012. Sustainable Manufacturing and Design: Concepts, Practices and 
Needs. Sustainability, 4(2), 154-174.

Shoemaker, P.J., Tankard, J.W., Lasorsa, D.L., 2004. How to build social science theories. SAGE Publications, Inc.

Sikdar, S. K., 2003. Sustainable development and sustainability metrics. American Institute of Chemical Engineers Journal, 49(8), 1928-1932.

Singh, R.K., Murty, H.R., Gupta, S.K., Dikshit, A.K., 2012. An overview of sustainability assessment methodologies. Ecological Indicators, 15(1), 281-299.

University of North California (UNC) Institute for the Environment, 2010. Sustainable Research Inventory [online]. Available from: http://www.ie.unc.edu/index.cfm [Accessed 14 January 2013].

US Department of Commerce (DOC), 2009. How does Commerce define Sustainable Manufacturing? [online]. Available from: http://trade.gov/index.asp [Accessed 28 May 2012].

US Department of Defense (DoD), 2011. Technology Readiness Assessment (TRA) Guidance [online]. Available from: http://www.acq.osd.mil/chieftechnologist/publications/docs/TRA2011.pdf [Accessed 17 November 2012].

US National Research Council (NRC), Board on Sustainable Development, 1999. Our Common Journey: A Transition Toward Sustainability. Washington, DC: National Academy Press.

Verheem, R., 2002. Recommendations for Sustainability Assessment in the Netherlands. Proceedings of the $22^{\text {nd }}$ Annual Conference of the International Association for Impact Assessment.

Watt, J.H., van den Berg, S., 1995. Research Methods for Communication Science. Allyn and Bacon, Needham Heights, MA.

Wikipedia, The Free Encyclopedia, Operational Definition [online]. Available from: http://en.wikipedia.org/wiki/Operational_definition [Accessed 19 November 2012].

Wikipedia, The Free Encyclopedia, Technology Readiness Level (TRL) [online]. Available from: http://en.wikipedia.org/wiki/Technology readiness level [Accessed 30 November 2012]. 